\title{
Photoprecursor Approach Enables Preparation of Well-Performing Bulk-Heterojunction Layers Comprising a Highly Aggregating Molecular Semiconductor
}

\author{
Mitsuharu Suzuki, ${ }^{\dagger}$ Yuji Yamaguchi, ${ }^{\star}$ Kohei Takahashi, ${ }^{\ddagger}$ Katsuya Takahira, ${ }^{\ddagger}$ \\ Tomoyuki Koganezawa, ${ }^{\#}$ Sadahiro Masuo, ${ }^{\perp}$ Ken-ichi Nakayama*, ${ }^{*}$ and Hiroko Yamada ${ }^{*}$, \\ ${ }^{\dagger}$ Graduate School of Materials Science, Nara Institute of Science and Technology, \\ 8916-5 Takayama-cho, Ikoma, Nara 630-0192, Japan \\ ${ }^{\star}$ Department of Organic Device Engineering, Yamagata University, \\ 4-3-16 Jonan, Yonezawa, Yamagata 992-8510, Japan \\ \#Japan Synchrotron Radiation Research Institute, \\ 1-1-1 Kouto, Sayo-cho, Sayo-gun, Hyogo 679-5198, Japan \\ ${ }^{\perp}$ Department of Applied Chemistry and Environment, Kwansei Gakuin University, \\ 2-1 Gakuen, Sanda, Hyogo 669-1337, Japan
}

Correspondence and requests for materials should be addressed to

H.Y. (hyamada@ms.naist.jp) or K.N. (nakayama@yz.yamagata-u.ac.jp) 


\section{Contents}

1. Effectiveness of conventional morphology modification treatments on the DTA:PC ${ }_{71} \mathrm{BM}$ system $\cdots \cdots \cdots \cdot \mathrm{S}-2$

2. Evaluation of active layers prepared with $30 \%$ of $o$-DCB cosolvent $\ldots \ldots \ldots \ldots \ldots \ldots \ldots \ldots \ldots \ldots \ldots \ldots \ldots \ldots \ldots \ldots \ldots \ldots \ldots \ldots$

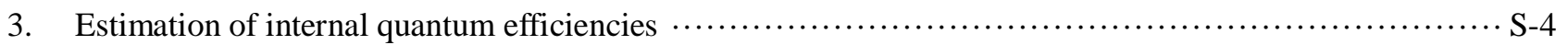

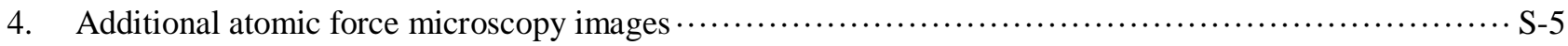

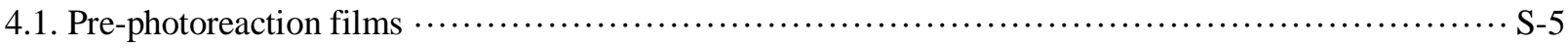

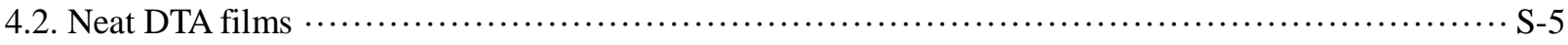

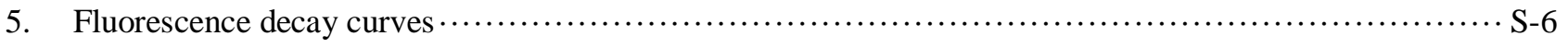

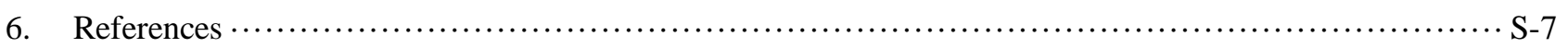




\section{Effectiveness of conventional morphology modification treatments on the DTA:PC ${ }_{71} B M$ system}

DTA:PC ${ }_{71} \mathrm{BM}$ films were subjected to three conventional morphology modification treatments: thermal annealing, addition of 1,8-diiodooctane (DIO), and solvent-vapor annealing as summarized in Table S1 (only the best result in each entry is shown). Thermal annealing worked moderately well, providing improved PCEs compared to the non-annealed sample. PCE was improved by almost four times from $0.41 \%$ (entry S1) to 1.59 or $1.56 \%$ at 100 or $140{ }^{\circ} \mathrm{C}$, respectively (entries S3 and S4). When higher temperatures of 180 and $220^{\circ} \mathrm{C}$ were applied, the photovoltaic performance was significantly deteriorated (entries S5 and S6), showing large leak currents at negative bias voltages. Addition of DIO did not show any positive effects (entries S7 and S8). Vapor annealing with tetrahydrofuran resulted in a considerable increase in FF (from 23.6 to 43.8\%), leading to an improved PCE of $0.77 \%$ (Entry S10). However, the improvement is much less significant compared to those observed when $o$-DCB cosolvent was used. Annealing with chloroform vapor resulted in considerable current leakage, affording a much lower PCE of $0.15 \%$ (entry S9).

Table S1. Effects of three different conventional postdeposition treatments on the DTA:PC ${ }_{71} \mathrm{BM}$ system. ${ }^{a}$

\begin{tabular}{|c|c|c|c|c|c|c|c|c|}
\hline thermal annealing $^{b}$ & entry & $\begin{array}{l}\text { annealing temp. } \\
\left({ }^{\circ} \mathrm{C}\right)\end{array}$ & $\begin{array}{c}J_{\mathrm{SC}} \\
\left.(\mathrm{mA} \mathrm{cm})^{-2}\right)\end{array}$ & $\begin{array}{l}V_{\mathrm{OC}} \\
(\mathrm{V})\end{array}$ & $\begin{array}{l}\mathrm{FF} \\
(\%)\end{array}$ & $\begin{array}{l}\text { PCE } \\
(\%)\end{array}$ & $\begin{array}{c}R_{\mathrm{S}} \\
\left(\Omega \mathrm{cm}^{2}\right)\end{array}$ & $\begin{array}{c}R_{\mathrm{P}} \\
\left(\Omega \mathrm{cm}^{2}\right)\end{array}$ \\
\hline & $\mathrm{S} 1$ & no annealing & 1.69 & 1.03 & 23.6 & 0.41 & 570 & 562 \\
\hline & $\mathrm{S} 2$ & 60 & 3.01 & 1.01 & 29.6 & 0.90 & 203 & 494 \\
\hline & $\mathrm{S} 3$ & 100 & 4.16 & 0.99 & 38.6 & 1.59 & 93 & 663 \\
\hline & S4 & 140 & 3.94 & 0.99 & 40.0 & 1.56 & 109 & 796 \\
\hline & S5 & 180 & 1.66 & 0.41 & 32.4 & 0.22 & 138 & 401 \\
\hline & S6 & 220 & 0.72 & 0.04 & 25.6 & 0.01 & 51 & 954 \\
\hline \multirow[t]{3}{*}{ DIO addition ${ }^{c}$} & entry & $\begin{array}{l}\text { DIO content } \\
(w t \%)\end{array}$ & $\begin{array}{c}J_{\mathrm{SC}} \\
\left(\mathrm{mA} \mathrm{cm}^{-2}\right)\end{array}$ & $\begin{array}{l}V_{\mathrm{OC}} \\
(\mathrm{V})\end{array}$ & $\begin{array}{l}\text { FF } \\
(\%)\end{array}$ & $\begin{array}{l}\text { PCE } \\
(\%)\end{array}$ & $\begin{array}{c}R_{\mathrm{S}} \\
\left(\Omega \mathrm{cm}^{2}\right)\end{array}$ & $\begin{array}{c}R_{\mathrm{P}} \\
\left(\Omega \mathrm{cm}^{2}\right)\end{array}$ \\
\hline & S7 & 1 & 0.27 & 0.14 & 26.7 & 0.01 & 428 & 558 \\
\hline & S8 & 3 & 0.09 & 0.31 & 31.2 & 0.01 & 2170 & 4948 \\
\hline \multirow[t]{3}{*}{$\begin{array}{l}\text { solvent-vapor } \\
\text { annealing }\end{array}$} & entry & $\begin{array}{l}\text { annealing } \\
\text { solvent }\end{array}$ & $\begin{array}{c}J_{\mathrm{SC}} \\
\left(\mathrm{mA} \mathrm{cm}^{-2}\right)\end{array}$ & $\begin{array}{l}V_{\mathrm{OC}} \\
(\mathrm{V})\end{array}$ & $\begin{array}{l}\mathrm{FF} \\
(\%)\end{array}$ & $\begin{array}{l}\text { PCE } \\
(\%)\end{array}$ & $\begin{array}{c}R_{\mathrm{S}} \\
\left(\Omega \mathrm{cm}^{2}\right)\end{array}$ & $\begin{array}{c}R_{\mathrm{P}} \\
\left(\Omega \mathrm{cm}^{2}\right)\end{array}$ \\
\hline & S9 & chloroform & 0.81 & 0.48 & 39.1 & 0.15 & 232 & 1730 \\
\hline & $\mathrm{S} 10$ & tetrahydrofuran & 1.96 & 0.90 & 43.8 & 0.77 & 113 & 1693 \\
\hline
\end{tabular}

${ }^{a}$ Active layers were deposited as described in the Experimental section of the main text except the postdeposition treatments. ${ }^{b} \mathrm{BHJ}$ films were annealed for $1 \mathrm{~min}$ at each temperature after photoreaction. ${ }^{c}$ Each amount of DIO was added to a cast solution. ${ }^{d}$ As-spun films were exposed to solvent vapor for $1 \mathrm{~min}$ after photoreaction. 


\section{Evaluation of active layers prepared with $30 \%$ of $o-D C B$ cosolvent}

The DTA:PC $\mathrm{PC}_{71} \mathrm{BM}$ films processed by using $30 \% o$-DCB showed good photovoltaic performance $(\mathrm{PCE}=1.93 \%$, Table S2). However, significant leak current was observed at bias voltages below $-1 \mathrm{~V}$ (Figure S1), presumably because of a small films thickness. Please note that $\mathrm{DTA}: \mathrm{PC}_{71} \mathrm{BM}$ films are generally very rough and there must be microscopic areas much thinner than the average thickness obtained by bulk measurement.

Table S2. Photovoltaic parameters of the best cell prepared with 30\% o-DCB cosolvent.

\begin{tabular}{ccccccc}
$\begin{array}{c}\text { active-layer } \\
\text { thickness }(\mathrm{nm})\end{array}$ & $\begin{array}{c}J_{\mathrm{SC}} \\
(\mathrm{mA} \mathrm{cm})^{-2}\end{array}$ & $\begin{array}{c}V_{\mathrm{OC}} \\
(\mathrm{V})\end{array}$ & $\begin{array}{c}\mathrm{FF} \\
(\%)\end{array}$ & $\begin{array}{c}\mathrm{PCE} \\
(\%)\end{array}$ & $\begin{array}{c}R_{\mathrm{S}} \\
\left(\Omega \mathrm{cm}^{2}\right)\end{array}$ & $\begin{array}{c}R_{\mathrm{P}} \\
\left(\Omega \mathrm{cm}^{2}\right)\end{array}$ \\
\hline 55 & 4.22 & 0.93 & 49.2 & 1.93 & 44 & 1312 \\
\hline
\end{tabular}

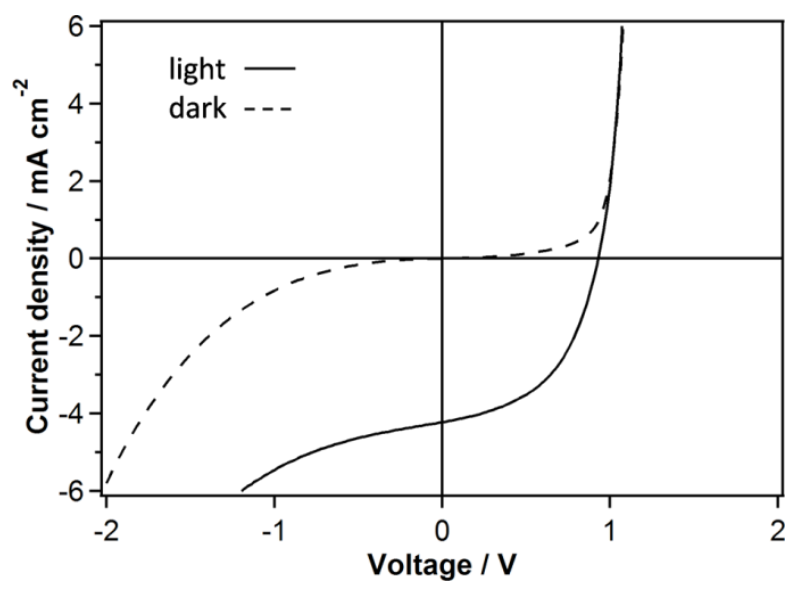

Figure S1. $J-V$ curves of a DTA:PC ${ }_{71} \mathrm{BM}$ BHJ OPV prepared with $30 \% o$-DCB cosolvent. 


\section{Estimation of internal quantum efficiencies}

Internal quantum efficiencies (IQEs) of the cells prepared with $0 \%$ or $20 \% o$-DCB were estimated from the external quantum efficiencies (EQEs) and photoabsorption according to the previously employed method by Yu et

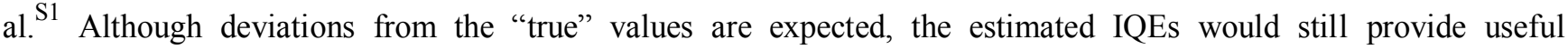
information in systematic comparison between devices. As shown in Figure S2, the maximum IQEs are estimated to be $31 \%$ at $425 \mathrm{~nm}$ and $89 \%$ at $430 \mathrm{~nm}$ for the cells prepared without and with $20 \% o$-DCB cosolvent, respectively.

(a)

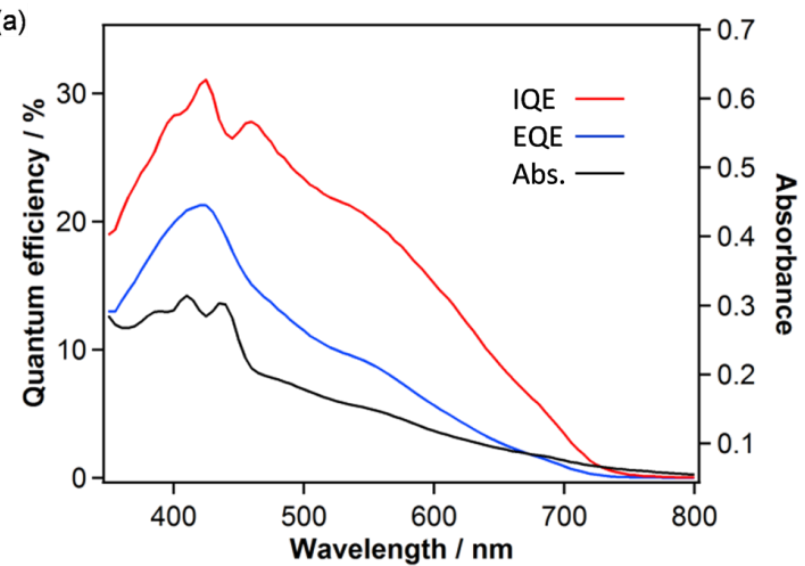

(b)

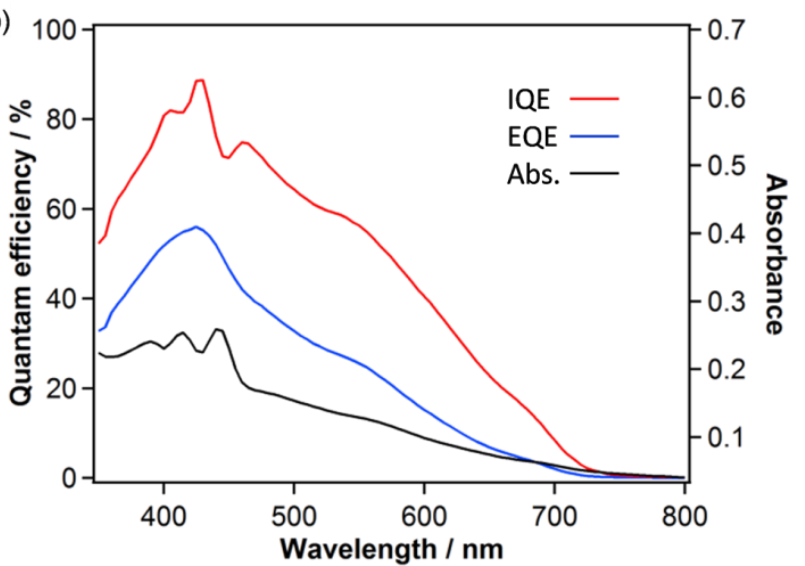

Figure S2. Photoabsorption, EQE, and IQE spectra of the devices prepared without (a) and 20\% (b) $o$-DCB cosolvent. 


\section{Additional atomic force microscopy images}

\subsection{Pre-photoreaction films}

(a)

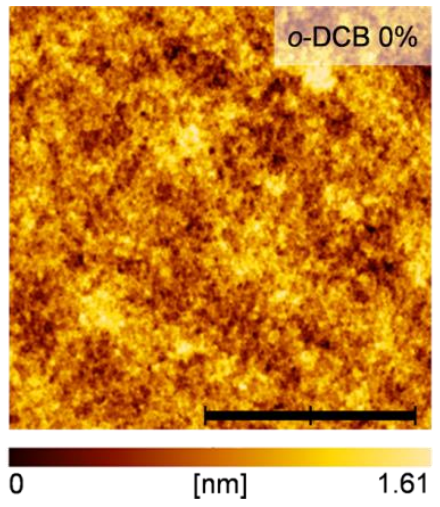

(b)

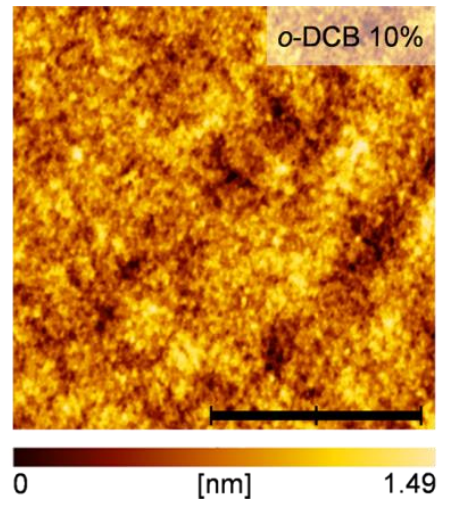

(c)

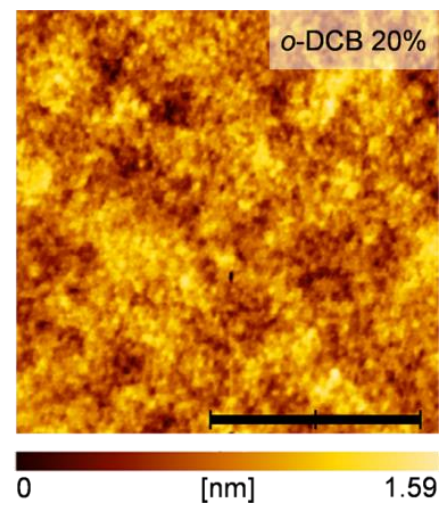

Figure S3. Tapping-mode AFM images of the DTADK:PC ${ }_{71} \mathrm{BM}$ films spin-coated on Glass/ITO/PEDOT:PSS using different amounts of $o$-DCB cosolvent: (a) $0 \%$, RMS roughness $=0.25 \mathrm{~nm}$; (b) $10 \%$, RMS roughness $=0.23 \mathrm{~nm}$; (c) $20 \%$, RMS roughness $=0.29 \mathrm{~nm}$. The scale bars correspond to $1 \mu \mathrm{m}$.

\subsection{Neat DTA films}

(a)

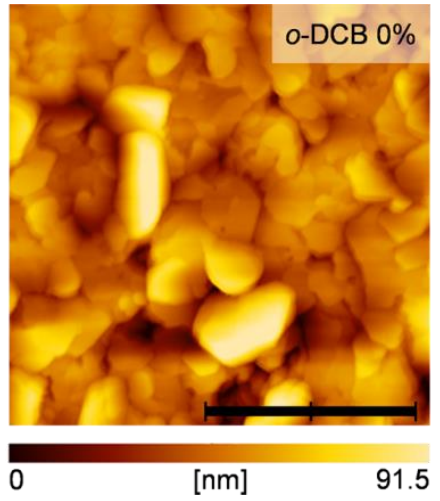

(b)

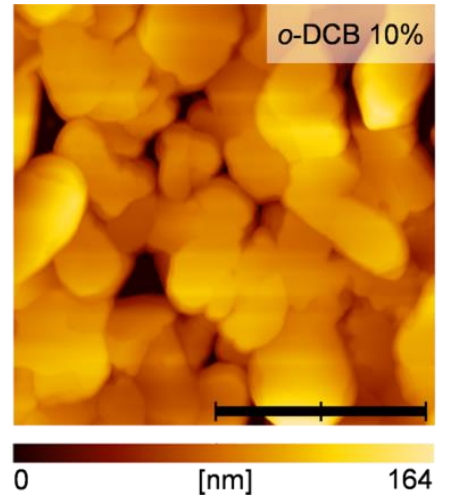

(c)

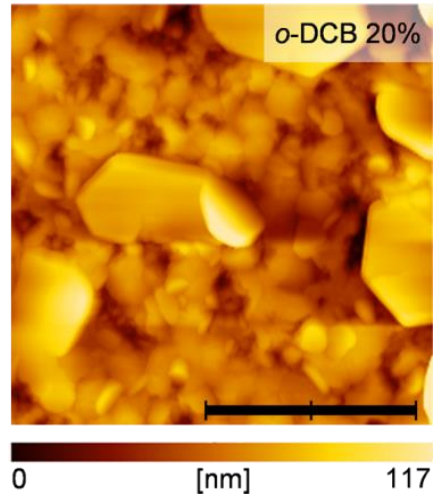

Figure S4. Tapping-mode AFM images of the DTA films prepared on glass/ITO/PEDOT:PSS by the photoprecursor approach with different amounts of $o$-DCB cosolvent: (a) $0 \%$, RMS roughness $=15.1 \mathrm{~nm}$; (b) $10 \%$, RMS roughness $=$ $25.1 \mathrm{~nm}$; (c) $20 \%$, RMS roughness $=18.8 \mathrm{~nm}$. The scale bars correspond to $1 \mu \mathrm{m}$. 


\section{Fluorescence decay curves}

Decay of the fluorescence from DTA domains was compared between DTA:PC ${ }_{71} \mathrm{BM}$ blend films deposited without and with $20 \% o$-DCB cosolvent (Figure S5). The experiments were performed in the same manner as described in our previous report. ${ }^{\mathrm{S} 2}$

It has been reported that the fluorescence decay kinetics considerably differ depending on measured locations within each sample. ${ }^{\mathrm{S} 2}$ Namely, highly fluorescent points (DTA-rich domains) generally show slow decay, while weakly fluorescent points (relatively well-mixed domains) show fast decay, reflecting the efficiency of the charge-transfer process. Here, fluorescence decay was measured at multiple points in each sample. The decay is faster for the 20\%-o-DCB sample at fast-decay points (solid lines in Figure S5), in good agreement with the assumption that charge-carrier generation is more efficient when $o$-DCB is added in a cast solution. On the other hand, the decay characteristics are essentially the same between the two samples at slow-decay points (dashed lines in Figure S5), indicating that the 20\%-o-DCB film has still some room for improvement in terms of morphology.

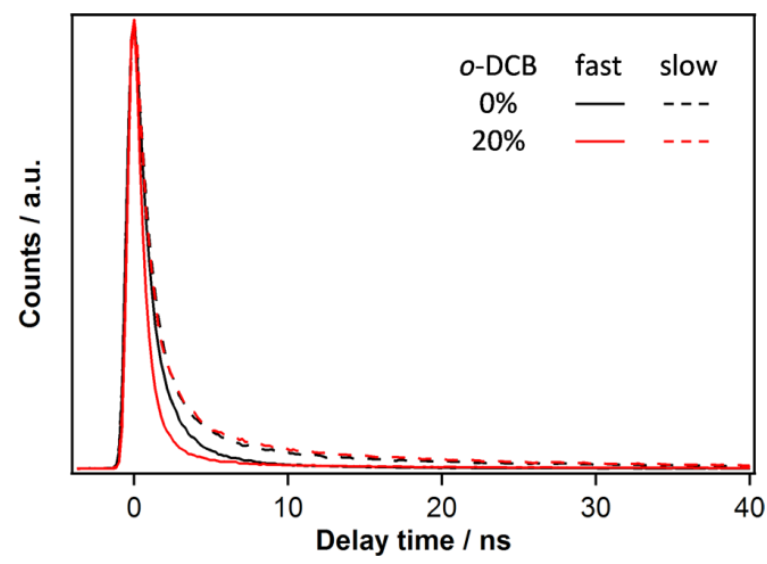

Figure S5. Fluorescence decay curves of DTA domains in DTA: $\mathrm{PC}_{71} \mathrm{BM}$ blend films prepared without (black) or with $20 \%$ (red) $o$-DCB cosolvent. The solid and dashed lines show the fastest and slowest decays, respectively, within the measured points in each sample. The sample films are the same as those used in the fluorescence image measurements shown in Figures 5a and 5c in the main text. The excitation wavelength is $405 \mathrm{~nm}$, and fluorescence is monitored through long-pass and short-pass filters to cut the excitation laser and fluorescence from $\mathrm{PC}_{71} \mathrm{BM}$, respectively. 


\section{References}

S1. Liang, Y.; Xu, Z.; Xia, J.; Tsai, S.-T.; Wu, Y.; Li, G.; Ray, C.; Yu, L. For the Bright Future-Bulk Heterojunction Polymer Solar Cells with Power Conversion Efficiency of 7.4\%. Adv. Mater. 2010, 22 (20), E135-E138.

S2. Masuo, S.; Sato, W.; Yamaguchi, Y.; Suzuki, M.; Nakayama, K.; Yamada, H. Evaluation of the Charge Transfer Efficiency of Organic Thin-Film Photovoltaic Devices Fabricated Using a Photoprecursor Approach. Photochem. Photobiol. Sci. 2015, 14, 883-890. 